\title{
Perceptions of Community Members at Lugelweni Mt Ayliff on Awareness about the Presence of Copper from Abandoned Mines
}

\author{
Hlalanathi Gwanya ${ }^{1}$, Jennifer Laifa2*, Gloria Miller ${ }^{3}$, Maria \\ Begonia $^{3}$ and Gregorio Begonia ${ }^{3}$ \\ 1Department of Biological \& Environmental Sciences, Walter Sisulu University, Nelson \\ Mandela Campus, South Africa \\ Research Article \\ Volume 3 Issue 2 \\ Received Date: March 11, 2019 \\ Published Date: April 04, 2019 \\ DOI: $10.23880 /$ jenr- 16000160
}

${ }^{2}$ Department of Natural Sciences \& Environmental Health, Mississippi Valley State University, USA

${ }^{3}$ Plant Physiology/Microbiology Laboratory, Department of Biology, Jackson State University, USA

*Corresponding author: Jennifer Laifa, Department of Natural Sciences \& Environmental Health, Mississippi Valley State University, 14000 HWY 82 W, IttaBena, Mississippi, 38941, USA, Tel: 6622543383; Email: nj.laifa@mvsu.edu

\section{Abstract}

The study was based on understanding the community's perceptions on the presence of heavy metals in their surroundings. At Lugelweni, Mt Ayliff there are abandoned copper mines located at Intsizwa Mountain which might be a potential source of metal contamination to Lugelweni community. The participants at Lugelweni village in Mount Ayliff were randomly selected and a questionnaire was distributed for assessing their awareness on the presence of the mines. The results showed that the participants do not know exactly when the process of mining started at Lugelweni and most of the participants were living in the area when the mining process was abandoned. Many participants agreed that there is water found at the mining area and do not know if the water is clean or not. About $60 \%$ of the participants do not know if the metals from the mines might be harmful to the environment or not. More than $80 \%$ of participants disagree that the metals leaching from the mines can be found in their agricultural soils. The results are an indication that the community members from Lugelweni Mt Ayliff are aware of the presence of the abandoned mines at Intsizwa Mountain. They are not aware of the effects that the metals from the abandoned mines might have on humans, agricultural soils, water, plants, and animals. There is a need for the South African Department of Environmental Affairs to conduct awareness campaigns in the areas where the abandoned mines are located.

Keywords: Copper; IntsizwaMountain; Mine; Lugelweni; Mount Ayliff; Heavy Metal 


\section{Introduction}

Assessment on the awareness of presence of minerals was performed to observe whether community members understand the impact caused by abandoned mines in the environment. The objective of the study was achieved by evaluating the perceptions of the community members towards copper. Copper is an essential element [1], required for vital physiological and biochemical functions in minute amount by the organisms [2-4] and can be toxic at high levels. It can cause anemia, arthritis, diabetes, headaches, heart attacks, hypertension, kidney and liver dysfunction, strokes and vitamin deficiencies in human [5]. Copper contamination in humans can be through water, soil, vegetables or plants.

The Intsizwa abandoned mines are situated in the heart of the IntsizwaMountain at Lugelweni Mount Ayliff. Due to high concentrations of copper found around the mines (unpublished data), the mines can pose threat to agriculture, human and animal health. Plants growing around the mine entrances have been found to accumulate high copper concentrations even beyond permissible levels (unpublished data). There is continuous mine effluent flowing from two mine entrances into the Ngweleni River. Ngweleni River is the source of drinking water for the community of Lugelweni.

There is very limited information or research study conducted on the influence of the abandoned mines in their neighbouring communities. There is little information available on heavy metal contamination in arable land more especially in small towns and rural areas [6]. There is no information available about the Intsizwa abandoned copper mines and their potential as sources of contamination. Therefore, the study will add value on the need for awareness campaigns and risk assessment on communities close to abandoned mines.

High elevated copper concentrations around the mine can potentially contaminate arable soils, water and vegetable at Lugelweni community. Effects of copper in agricultural activity, food contamination and food safety have not yet been evaluated from Lugelweni community. The existence of the abandoned mines can pose various health and environmental concerns which are usually neglected. Communities and the environments in close vicinities of the mines are mostly negatively influenced through human and animal health. For the South Africa Department of Environmental Affairs to be able to conduct awareness campaigns on the effects of abandoned mines to the communities such studies are required. Studies that focus on the evaluation of the awareness and perceptions of the possible effects caused by the mines and abandoned mines to the community in close proximities are needed.

There are abandoned mines around the world which can potentially pose detrimental effects to the environment. These types of mines and their effects have been neglected for a long time. Every country with depleting mining resources is increasingly having a number of abandoned mines. There are 500 abandoned mines in Australia, 10139 in Canada, 10000 in the United Kingdom, 557650 in the United States, 1000 in Sweden and 128 in Ireland. South Africa has about 134 abandoned mines [7]. The abandoned mines influence the soil, water, plants and animals as these are at risk of change in their normal state $[8-10,6]$. The abandoned mines do not only pose detrimental health risks to communities in close proximity to the mine but also a major contributor to poverty and socio-economic systems [7].

Soils that are contaminated with high levels of metal concentration lose their stable state. They are excavated or the top soil is removed leading to soil erosion and activity. Water activity is also threatened by accumulation of metals changing the water $\mathrm{pH}$ and affecting aquatic habitats [6]. Agricultural activity is at risk when soil and water are contaminated because production yield is affected $[8,9]$.

Vegetation is also affected in the abandoned mine area as there is a decrease in normal vegetation present or growing in close proximities. The quality of vegetation deteriorates and the physical appearance is changed [8]. Only those plants that are classified as excluders or hyperaccumulators or metal tolerant persist growing in those areas. Therefore, there is contamination of food chain as animals and humans consume these plants without knowing that they might be contaminated.Humans can buy meat from animals that have fed from these metal contaminated areas.

There are very few studies conducted to find the effects of the mines to the health of the people living around the mine. In Malaysia Hassan NA [11] evaluated the effects of cyanide where cyanide was found to threaten the ecosystems and the population in surrounding communities. The results from their study revealed that high poor health was caused by the accumulation of cyanide in the community. In Korea, Kim $S$, et al. [12] investigated the health effects caused by the abandoned metal mines. Their results indicated that the abandoned mine caused high accumulation of copper, cadmium, arsenic, lead and zinc in the drinking water, air 
and agricultural products. These high concentrations of metals contributed to high number of community members diagnosed with early kidney dysfunctions, urinary problems and bone mineral density. In South Africa there is limited information on the evaluation of the effects of abandoned mines to the communities residing in close vicinities. If the mines and/or abandoned mines produce detrimental health effects to the community it is important to conduct relevant studies in an attempt to alert the community around the mines. Evaluating the perceptions of the community members towards abandoned mines must be reported in order for the department of Environmental Affairs conduct to awareness campaigns.

The aim of the present study was to investigate the perceptions of the community members regarding the presence and effects of abandoned copper mines. We hypothesised that the responses from the participants will not significantly differ from each other regardless of the duration of stay at Lugelweni.

\section{Methodology}

The sample included participants residing at Lugelweni Mount Ayliff. All the 90 participants selected were visited at their households. There were 56 female participants and 34 male participants. The 56 females interviewed ranged in age from 21 to 81 years while the 34 male participants ranged in age from 17 to 76 years. All the participants were Black and speak Xhosa. The researcher interpreted the language to those who did not understand English as the questionnaire was in English. The duration of stay for the participants ranged from 1 to 81 years. The data were collected by the administration of questionnaires to selected participants. The measuring scale was formulated by a five point selection relative to the appropriate answer and ranged from strongly agree (point 1) to strongly disagree (point 5).

\section{Limitations/Constraints of the Study}

The limitations of the study were the lack of equal representation of all the participants residing at Lugelweni. This was due to participants' commitments at work, schools and meetings when administering the questionnaires.

\section{Data Analysis}

The data were analysed using SPSS version 24. Data were analysed using frequency percentages and Chisquare to determine the association of responses in relation to the duration of stay by the participants of the
Lugelweni community. The statistical criterion for significant difference was set at $\mathrm{p}<0.05$.

\section{Results}

\section{Demographics}

The community of Lugelweni consisted of 429 households and 90 participants were surveyed. There were 34 males and 56 females. The ages of the participants from Lugelweni community ranged from 17 to 81 years old. The years of stay by the participants at Lugelweni ranged from 1 year to 81 years.

\section{Descriptive statistics analysis}

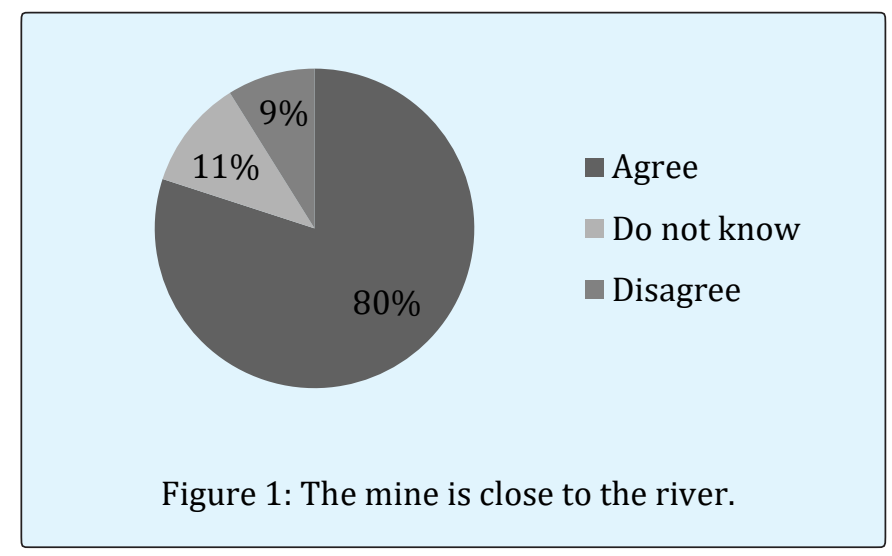

When the participants were asked if the mine is close to the river, eighty $\%$ of the participants agreed that the mine is close to the river while $11 \%$ and $9 \%$ (Figure 1 ) did not know and disagreed, respectively.

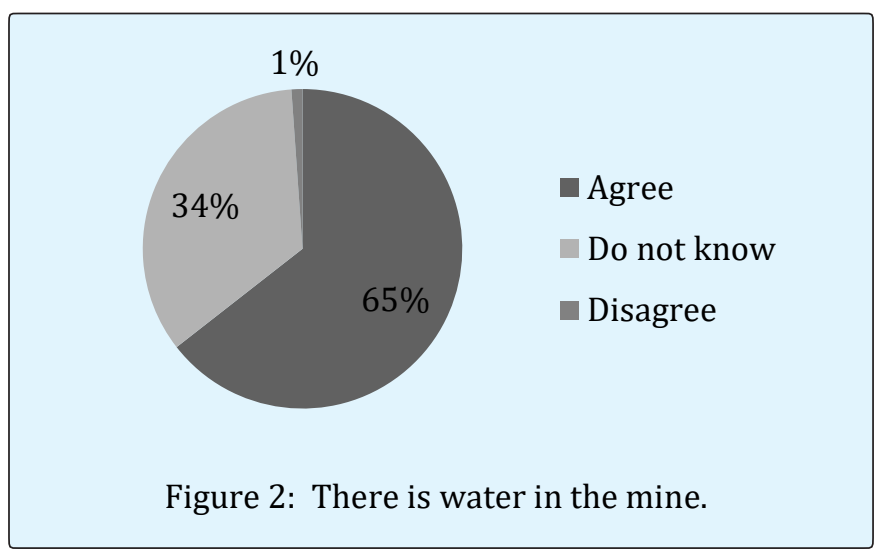

A large number of participants at $65 \%$ (Figure 2) agreed that there is water in the mine. Only $1 \%$ of the participants claimed that there is no water in the mine. 


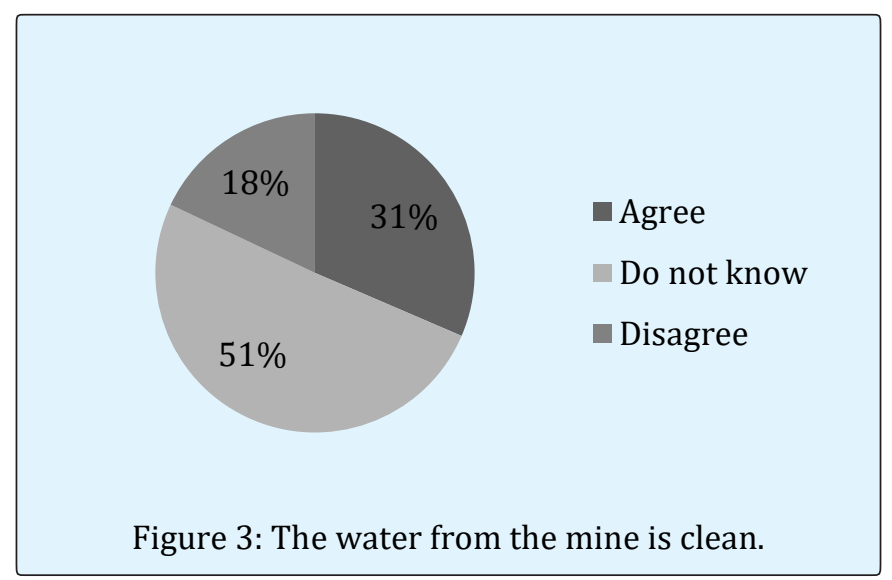

Fifty-one \% of the surveyed participants (Figure 3) indicated that the water in the mine is not clean. Thirtyone $\%$ of the participants agreed while $18 \%$ did not know.

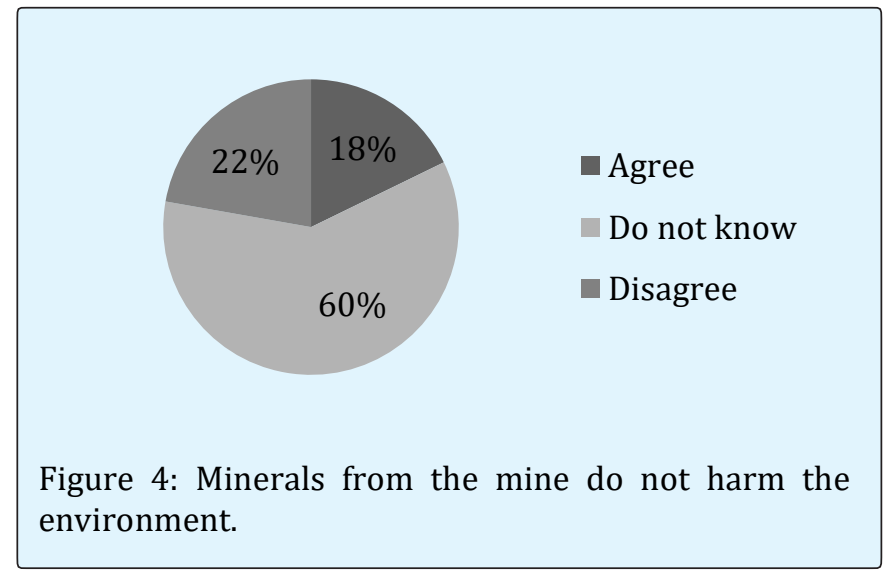

The results (Figure 4) show that the majority of the participants did not know the threats posed by the minerals to the environment. As a result, $60 \%$ of the participants did not know the potential harm the minerals from the mine pose to the environment while $22 \%$ disagreed and $18 \%$ agreed.

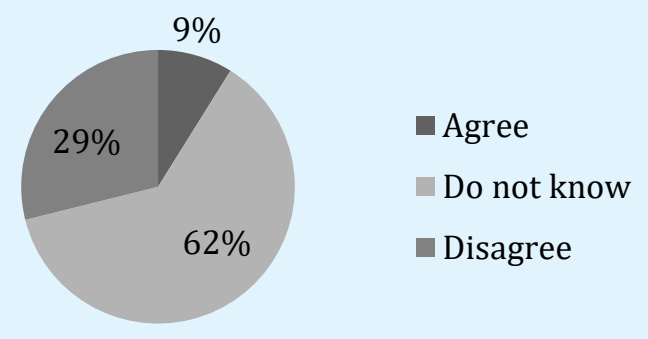

Figure 5: Minerals from the mine close to the village are also found in the soil.
The response from the surveyed participants indicated that there is little information that is known about metal contamination. A small percentage of $9 \%$ agreed that the minerals are found in the soil and $29 \%$ disagreed (Figure $5)$.

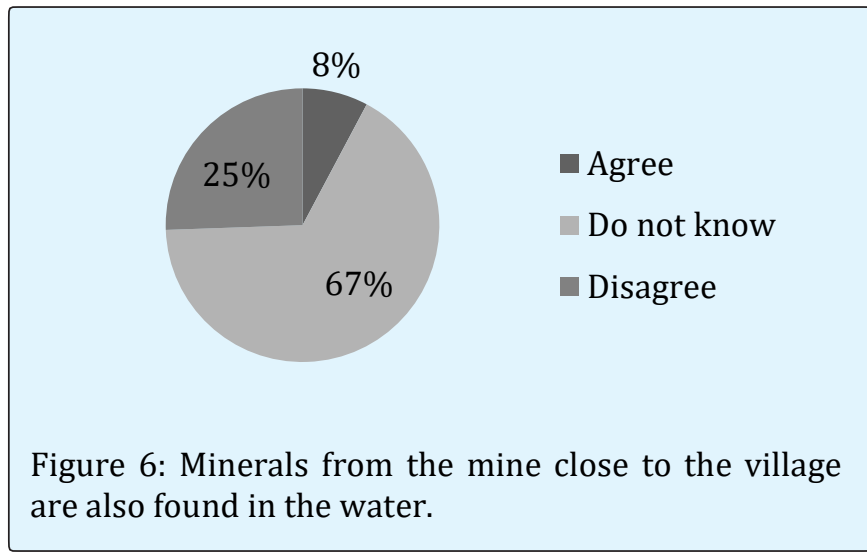

A small percentage of $8 \%$ agreed that minerals are also found in water while $67 \%$ did not know and $25 \%$ disagreed (Figure 6).

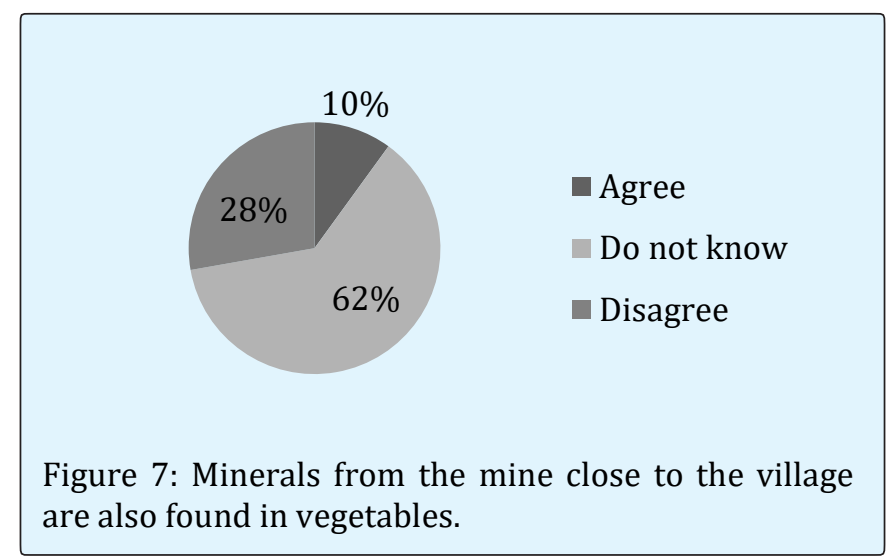

The same trend of results (Figure 7) similar to those found on the responses on the presence of minerals in water was observed.

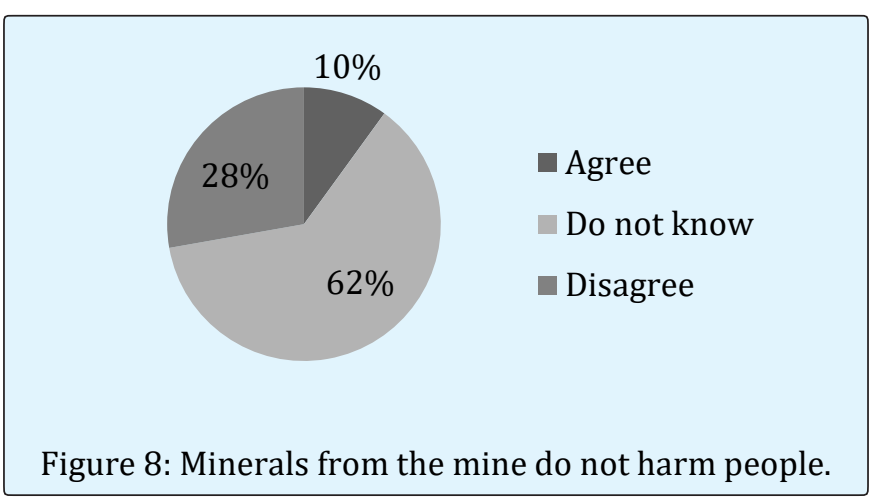


The results show that there is very little information known about minerals (Figure 8). Only $28 \%$ of the participants indicated that the minerals are dangerous to people while $62 \%$ did not know.

\section{Association between responses of participants and duration of stay at Lugelweni}

\begin{tabular}{|c|c|c|c|c|c|c|c|c|c|c|c|c|c|c|c|c|c|c|c|c|c|c|c|c|}
\hline & \multicolumn{3}{|c|}{ Question1 } & \multicolumn{3}{|c|}{ Question 2} & \multicolumn{3}{|c|}{ Question 3} & \multicolumn{3}{|c|}{ Question 4} & \multicolumn{3}{|c|}{ Question 5} & \multicolumn{3}{|c|}{ Question 6} & \multicolumn{3}{|c|}{ Question 7} & \multicolumn{3}{|c|}{ Question 8} \\
\hline $\begin{array}{l}\infty \\
\stackrel{\varpi}{\varpi} \\
ٍ\end{array}$ & 离 & $\begin{array}{l}3 \\
0 \\
\vdots \\
\vdots \\
\vdots \\
\vdots \\
\vdots \\
0 \\
0\end{array}$ & 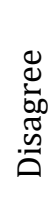 & 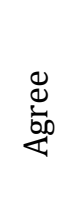 & $\left|\begin{array}{c}3 \\
0 \\
\vdots \\
\vdots \\
\vdots \\
0 \\
\vdots \\
0 \\
0\end{array}\right|$ & 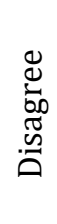 & 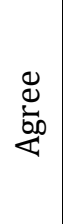 & 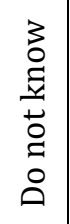 & 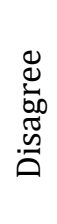 & 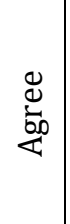 & 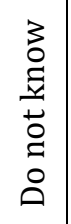 & 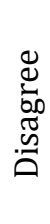 & 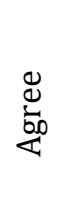 & 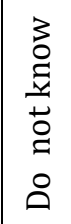 & 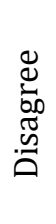 & 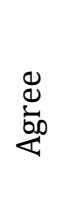 & 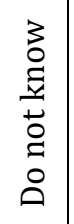 & 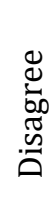 & 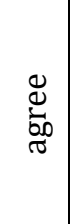 & 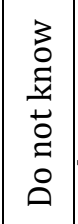 & 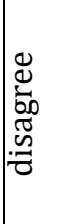 & 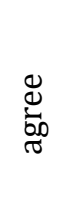 & 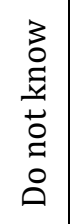 & 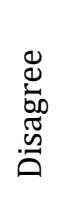 \\
\hline$\stackrel{a}{a}$ & 7 & 1 & 1 & 2 & 6 & 1 & 1 & 7 & 1 & 3 & 5 & 1 & 1 & 3 & 5 & 1 & 3 & 5 & 2 & 2 & 5 & 1 & 4 & 4 \\
\hline $\begin{array}{l}\stackrel{\sigma}{\vec{r}} \\
\stackrel{1}{\circ}\end{array}$ & 7 & 2 & 0 & 5 & 4 & 0 & 0 & 8 & 1 & 0 & 5 & 4 & 0 & 7 & 2 & 0 & 6 & 3 & 1 & 5 & 3 & 2 & 6 & 1 \\
\hline $\begin{array}{l}\text { શે } \\
\text { ஸे } \\
\text { ஸे }\end{array}$ & 8 & 3 & 0 & 6 & 5 & 0 & 4 & 5 & 2 & 0 & 8 & 3 & 2 & 6 & 3 & 1 & 6 & 4 & 2 & 6 & 3 & 2 & 5 & 4 \\
\hline $\begin{array}{l}\text { a } \\
m \\
\vdots \\
\text { r }\end{array}$ & 10 & 1 & 0 & 8 & 3 & 0 & 3 & 5 & 3 & 1 & 6 & 4 & 1 & 6 & 4 & 1 & 6 & 4 & 1 & 6 & 4 & 2 & 6 & 5 \\
\hline $\begin{array}{l}\stackrel{9}{+} \\
\text { ’ } \\
\text { + }\end{array}$ & 20 & 0 & 1 & 17 & 4 & 0 & 9 & 6 & 6 & 4 & 14 & 3 & 1 & 15 & 5 & 2 & 15 & 4 & 2 & 15 & 4 & 1 & 16 & 4 \\
\hline 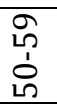 & 7 & 3 & 1 & 7 & 4 & 0 & 1 & 8 & 2 & 2 & 8 & 1 & 2 & 8 & 1 & 0 & 10 & 1 & 1 & 9 & 1 & 0 & 11 & 0 \\
\hline $\begin{array}{l}9 \\
0 \\
1 \\
0\end{array}$ & 13 & 2 & 0 & 12 & 3 & 0 & 7 & 5 & 3 & 4 & 8 & 3 & 1 & 10 & 4 & 2 & 10 & 3 & 1 & 10 & 4 & 4 & 9 & 1 \\
\hline $\begin{array}{l}9 \\
\stackrel{9}{1} \\
\vdots \\
0\end{array}$ & 2 & 0 & 0 & 1 & 1 & 0 & 2 & 0 & 0 & 1 & 1 & 0 & 0 & 2 & 0 & 0 & 2 & 0 & 0 & 2 & 0 & 0 & 2 & 0 \\
\hline $\begin{array}{l}9 \\
\infty \\
1 \\
\infty \\
\infty\end{array}$ & 1 & 0 & 0 & 1 & 0 & 0 & 1 & 0 & 0 & 0 & 1 & 0 & 0 & 1 & 0 & 0 & 1 & 0 & 0 & 1 & 0 & 0 & 1 & 0 \\
\hline $\mathrm{X}^{2}$ & & .681 & & & 0.218 & & & 0.075 & & & 0.534 & & & 0.747 & & & 0.692 & & & 0.761 & & & 0.233 & \\
\hline
\end{tabular}

Table 1: Responses of participants in relation to duration of stay at Lugelweni.

Table 1 showed that twenty participants who have lived between 40-49 years at Lugelweni agreed that the mine is close to the river. Only 1 participant who has lived there for 81 years agreed that the mine is close to the river. Three participants who stayed between 20-29 years did not know whether the mine is close to the river or not. Another 3 participants who lived between 50-59 years did not know if the mine is close to the river. A single participant who stayed for less than 10 years at Lugelweni community disagreed that the mine is close to the river.There were no significant differences in the responses on whether the mine is close to the river, as $\chi^{2}$ $=\sum_{\mathrm{i}} \sum_{\mathrm{j}}(\mathrm{Oij}-\mathrm{Eij}) / \mathrm{Eij}, \chi^{2}=0.681$ is greater than the level of significance $\alpha=0.05$. Therefore, the null hypothesis was accepted stating that the different numbers of years lived by participants have no influence on the responses from various participants.

Seventeen participants who stayed at Lugelweni between 40-49 years agreed that there was water in the mine and was supported by 12 participants who lived there between 60-69 years. Six participants did not know whether the water in the mine is clean. Only a single participant who lived there for less than 10 years disagreed that there is water in the mine.There were no significant differences in the responses on whether there is water in the mine, as $\chi^{2}=\sum_{\mathrm{i}} \sum_{\mathrm{j}}(\mathrm{Oij}-\mathrm{Eij}) / \mathrm{Eij}, \chi^{2}=0.218$ is greater than the level of significance $\alpha=0.05$. Therefore, the null hypothesis was accepted indicating that the responses were the same in different duration periods. 


\section{Journal of Ecology \& Natural Resources}

The results from Table 1 indicated that 9 participants who stayed between 40-49 years agreed that the water in the mine is clean. Seven participants who lived between 60-69 years also agreed that the water in the mine is clean. Seven participants who spent between 0-9 years there did not know whether the water in the mine is clean. Participants who stayed between 10-19 years and between 50-59 years both comprising of 8 participants did not know. Six participants who spent between 40-49 years disagreed that the water in the mine is clean.There were no significant differences in the responses on whether the water in the mine is clean, $\chi^{2}=\sum_{\mathrm{i}} \sum_{\mathrm{j}}(\mathrm{Oij}-$ $\mathrm{Eij}) / \mathrm{Eij}, \chi^{2}=0.075$ is greater than the level of significance $\alpha$ $=0.05$. Therefore, we fail to reject the null hypothesis.

Fourteen participants who spent between 40-49 years at Lugelweni did not know whether minerals from the mine do not harm the environment. This was supported by participants who have lived between $20-29$ years, 50 59 years and 60-69 years, all consisting of 8 participants. Four participants who lived between 60-69 years agreed that the minerals from the mine do not harm the environment whereas 4 participants who spent between 10-19 years disagreed. Four participants who lived between 30-39 years also disagreed on whether the minerals from the mine do not harm the environment (Table 1). There were no significant differences in the responses of respondents on whether the minerals from the mine do not harm the environment, as $\chi^{2}=\sum_{\mathrm{i}} \sum_{\mathrm{j}}(\mathrm{Oij}-$ $\mathrm{Eij}) / \mathrm{Eij}, \chi^{2}=0.534$ is greater than the level of significance $\alpha$ $=0.05$. Therefore, the null hypothesis is accepted. This is indicates that duration does not have an effect on the knowledge about the effects of the mine to the environment.

Table 1 displayed that 15 participants who spent between 40-49 years at Lugelweni did not know whether the minerals from the mine are found in the soil or not. This was supported by 8 participants who stayed between 50-59 years. Ten participants who lived between 60-69 years also did not know whether the minerals from the mine are found in the soil. Five participants who stayed between 0-9 years disagreed on whether the minerals from the mine are found in the soil.There were no significant differences on whether the minerals from the mine are also found in the soil, as $\chi^{2}=\sum_{\mathrm{i}} \sum_{\mathrm{j}}(\mathrm{Oij}-\mathrm{Eij}) / \mathrm{Eij}$, $\chi^{2}=0.747$ is greater than the level of significance $\alpha=0.05$. Therefore, the null hypothesis was accepted, indicating that, different duration periods do not influence different responses meaning that the community is not aware that the minerals can be found on the soil.
The results (Table 1) displayed that 15 participants who spent between 40-49 years at Lugelweni do not know that minerals from the mine are found in the water. No more than 5 participants who lived between 0-9 years, 20-29 years and 30-39 years disagreed on whether minerals from the mine are found in water.

There were no significant differences on whether the minerals from the mine close to the village are also found in the water, $\chi^{2}=\sum_{\mathrm{i}} \sum_{\mathrm{j}}\left(\mathrm{Oij}\right.$-Eij)/Eij, $\chi^{2}=0.692$ is greater than the the level of significance $\alpha=0.05$. Therefore, the null hypothesis is accepted. This is an indication that the community members are not aware that water can contain minerals from the mine.

The results from Table 1 demonstrated those 15 participants, 9 participants and 10 participants who spent between 40-49 years, 50-59 years and 60-69 years, respectively, at Lugelweni did not know whether minerals accumulate in vegetables. Only five participants who stayed there between 0-9 years disagreed on whether minerals from the mine are found in vegetables. There were no significant differences in the responses on whether minerals from the mine close to the village are also found in vegetables, as $\chi^{2}=\sum_{\mathrm{i}} \sum_{\mathrm{i}}(\mathrm{O} \mathrm{ij}-\mathrm{Eij}) / \mathrm{Eij}, \chi^{2}=0.761$ is greater than the level of significance $\alpha=0.05$. Therefore, the null hypothesis is accepted. The results show that, the time spent does not affect the responses meaning that information known by participants who have lived there for 80 years is the same as the participant who has lived there for a year.

Sixteen participants who spent between 40-49 years at Lugelweni did not know whether minerals from the mine do not harm people. The same response was given by participants who lived between 50-59 years and by those who stayed between 60-69 years. Only four participants who lived at Lugelweni between 0-9 years disagreed that minerals from the mine do not harm people. There were 2 participants who stayed between 20-29 years and those who lived between 30-39 years who agreed that the mineral from the mine do not harm people (Table 1). There were no significant differences in the responses on whether minerals from the mine do not harm people, as $\chi^{2}=\sum_{\mathrm{i}} \sum_{\mathrm{i}}(\mathrm{O} \mathrm{ij}-\mathrm{Eij}) / \mathrm{Eij}, \chi^{2}=0.233$ is greater than the level of significance $\alpha=0.05$. Therefore, the null hypothesis is accepted. This shows that, the community members are not informed about the potential dangerous impacts the mine have to human health. 


\section{Discussion}

The research study focused on the perceptions of the Lugelweni community members about the impact posed by abandoned Intsizwa mine to the environment; agricultural activities, soil, water and animals and humans. According toMaramba NPC, et al. $[13,8]$ the detrimental impacts posed by the abandoned mines are the accumulation of heavy metals in the environment resulting to human health complications.Wright CY, Nkosi $\mathrm{V}[14,15]$ also agree that heavy metals affect human health. Soil degradation, loss of vegetation and agricultural production, decline of aquatic biodiversity, sedimentation, and contamination of drinking water, soil and air pollution were found by Zhenqi $H[16,17,9,13]$ to be the effects of abandoned mines [18]. Mehta PSfound out those abnormalities in ecology, wildlife and local climate can be caused by the presence of abandoned mines.

The Intsizwa abandoned mine water effluents deposits to the Ngeleni River and the Lugelweni community are aware of the locations of the mines relative to the river. Water is a metal transporter, transferring minerals from high mineral rich source to mineral free environments such as rivers, dams, free lands or farming lands [13]. Soil and wind or air are the second major transpoters after water $[19,20]$. Therefore, mines situated very close to the river cause high river water contamination through the mineral water run-offs. According toMaramba NPC, et al. [13] non-active mines generate enough metallic contaminants to accumulate in the surface and underground water through acid mine drainage where concentrations beyond permissible level alters water quality, aquatic biodiversity and aquatic habitats. A supporting statement from Adabanija MA (2014) [17], suggested that water in mine is extremely metal concentrated, as water $\mathrm{pH}$ and temperatures as well as presence of oxygen influence high solubility of metals available in the mine. Therefore, water outflows/ run-off from the mines are highly concentrated with metals potentially posing severe dangers to aquatic habitats $[15,14,8]$.

The information and understanding about the impact posed by the Intsizwa abandoned mine in mineral accumulation to streams is not known by the community. In the study conducted byMaramba NPC, et al. [13] it was found that the abandoned mercury mine contaminated streams and aquatic animals were found with high mercury concentration beyond the standard allowable concentrations. To highlight the extreme impact of mining effluents, Appleton JD [8] reported that several dead water buffalos were found with high concentration of cyanide poisoning caused by high metal contamination in water.

The results from the present study revealed not enough awareness about the negative effects caused by the mine to the environment and human health as well as mineral accumulation in soil and vegetables from the community. KimS, et al. [12] stated that community members have poor knowledge regarding existence of abandoned mines and as a source influencing environmental contamination and health impacts. [12]KimS, et al. Further argued that awareness is required where the media raise national public concerns. In contrast, in the study conducted byWright CY [14], participants were aware about the dust from the abandoned mine nearby and were aware about the resulting diseases influenced by exposure to contaminated air or dust. Vazquez MC [21] found that the communities living and working near two metal plant processing stations were aware of the dangerous effects caused by metal waste. They were aware of the health diseases and devastating destruction to the environment either through air pollution or dust and water or soil contaminations. Consumption of metal contaminated food and water can lead to various health complications such as kidney, urinary and heart problems. Exposure to metal dust from abandoned mine contributes to the respiratory health complications $[16,14,13,11,8]$. According to Mbaya RP [22], detrimental effects exhibited by the abandoned mine to the environment and human heath hugely influences a matter of public concern to increase awareness to communities living in close proximity. In Australia, the community residing around the coal mining sites were exposed to air pollution caused by the mine. They complained to the department of Environmental Affairs, newspaper and the public health unit about the discomforts they were experiencing due to air pollution [23].

The mining residues are acidic and rich in metal constituents polluting agricultural fields through irrigation with metal concentrated water or dust. The participants from the present study are not aware about metal accumulation in agricultural products. Appleton JD [8] found that when agricultural farmers were irrigating with river contaminated water, there was a massive decline in their agricultural rice yields from $6000 \mathrm{~kg} / \mathrm{ha}$ to $3000 \mathrm{~kg} / \mathrm{ha}$ over a 10 year period. Adabanija MA [17] argue that the resulting effects cause loss of soil quality and soil degradation due to the presence high metals available resulting to crop accumulation and declining of crop/plant growth, quality of the crops and food contamination. Similar results were found byKim S, et al. 
[12] where rice and barley crops planted in near abandoned mines were found with high levels of metals which were the primary sources of food contamination.

There are communities residing around active mines or abandoned mines who are aware of the health and environmental impacts caused by mines. There are communities that have taken preventative mechanisms on continuous exposure to mining discharges which include air pollution or dust. Such communities file complaints about the continuous mining discharges to related departments; this shows a high level of awareness and critical concerns about abandoned mines. Urban areas or developed countries are aware of the impacts caused by the abandoned mines in their environment and to human health compared to rural or developing countries. Urban communities are more informed about the dangers of mineral contaminations because of their developed educational status or the availability of information centres, libraries and their advancement in the social technological systems. Rural communities are poor and most likely to have low educational background causing difficulties in acquiring concerns information centres, social technological communication systems, poorer governmental management and spreading of information.

The different time spent by the community members at Lugelweni does not influence the perceptions about the effects posed by the Intsizwa abandoned mine. The perception of a 20 year old member of the community was observed from the present study to be the same as that of an 80 year old member of the community of Lugelweni. The present study indicates that the perceptions of a community member who has lived less than a year compared to the members that have stayed in the community for more than 70 years are actually the same.

\section{Conclusions and Recommendations}

The Lugelweni community are well informed of where the Intsizwa abandoned mine is situated relative to the distance to the river. They are also aware that there is water in the mine. The mines close to the river pose high possibility of contaminating the river water. There is a possibility for the water from the mine entering the water from the river. Members of the community are not aware that the water in the mines is not clean. Water from the mines is highly concentrated with solubilised heavy metals which accumulated in the ground water and surface water.
The community of Lugelweni are not aware about the impact the mine cause to the environment and human health which are influenced by the poor knowledge of mineral accumulation to soil and vegetables. Concentrated mineral content in arable soil influences accumulation of metals in vegetables resulting in low quality agricultural products and food contamination. Consumption of contaminated food, water and exposure to polluted air or dust can trigger cardiovascular disorders, respiratory disorders and urinary disorders. The conclusions of the present study of Lugelweni highly recommend that the South Africa Department of Environmental Affairs conduct awareness campaigns about the impact caused by the abandoned mines. The present study also suggests that the Department of Health come and evaluate the health status due to the health effects that are potentially caused by the mine. It is also recommended that the South Africa Department of Agriculture, Forestry and Fisheries give awareness on the sign and symptoms when there is high accumulation of metals in agricultural fields. It is also recommended that the institutions of Higher learning engage the community as part of community engagement by institution to remediate metals that may be found in arable soils and water.

\section{References}

1. Appenroth KJ, Krech K, Keresztes A, Fischer W, Koloczek H (2010) Effects of nickel on the chloroplasts of the duckweeds Spirodela polyrhiza and Lemna minor and their possible use in biomonitoring and phytoremediation. Chemosphere 78(3): 216-223.

2. Bhargava A, Carmona FF, Bhargava M, Srivastava S (2012) Approaches for enhanced phytoexctraction of heavy metals. J Environ Manag 105: 103-120.

3. Shakya PR, Khwaounjoo NM (2013) Heavy metal contamination in green leafy vegetables collected from different market sites of kathmandu and their associated health risks. Scientific World 11(11): 3742.

4. Taiz L, Zeiger E (2006) Plant physiology, Sinauer Associates, Inc, Sunderland, Massachusetts.

5. Lokeshappa B, Shivpuri K, Tripathi V, Dikshit AK (2012) Assessment of Toxic Metals in Agricultural Produce. Food and Public Health 2(1): 24-29. 
6. Cukrowska EM, Makiese L, Tutu H, Chimuka LK (2012) The impact of Gold murcury pollution in the Witswaterand Basin, South Africa. Preceeding of the Annual workshop IGCP/SIDA no 594, 15. Namibia.

7. Van Zyl D, Sassoon M, Digby C, Fleury AM, Kyeyune S (2002) Mining for the Future Main Report, Mining, Minerals and Sustainable Development, International Insitute for Environment and Development.

8. Appleton JD, Week JM, Calves JPS, Beinhoff C (2006) Impacts of murcury contaminated mining waste on soil quality, crops, bivalves and fish in the Naboc River area, Mindanao, Philippines. Science Total Environ 353(2-4): 198-211.

9. Cortes-Maramba N, Reyes JP, Francisco-Rivera A, Akagi H, Sunio R, et al.(2006) Health and environment assessment of mercury exposure in a gold ming commuinity in Western Mindanao, Philippines. J Environ Manag 81(2): 126-134.

10. Nkulu BLAJ (2012) Pathways of exposure to cobalt in populations living in Katang, DR Congo. Preceedings of the Annual workshopmIGCP/SIDA No 594, 13. Namibia.

11. Hassan NA, Sahani M, Hod R, Yahya NA (2014) A study on exposure to cyanide among a commuity living near a gold mine in Malaysia. J Environ Health $77(6): 42-48$.

12. Kim S, Kwon HJ, Cheong K, Choi K, Jang JY, et al. (2008) Investigation on health effects of an abandoned metal mine. J Korean Med Sci 23(3): 452458.

13. Maramba NPC, Reyes JP, Tfrancisco-Rivera A, Crisanta L, Panganiban R, et al. (2006) Environmental and human exposure assessment monitoring of communities near an abandoned mercury mine in the Philippines: A toxic legacy. J Environ Manag 81(12): 135-145.
14. Wright CY, Matooane M, Oosthuizen MA, Phala N (2014) Risk perceptions of dust and its impacts among communities living in a mining area of the Witwatersrand, South Africa. Clean Air J 24(1): 22-27.

15. Nkosi V, Wichman J, Voyi K (2015) Chronic respiratory disease among the elderly in South Africa: any association with proximity to mine dumps?. Environmental Health 14(33): 2-8.

16. Zhenqi H, Peijun W, Jing L (2012) Ecological Restoration of abandoned mine land in China. JRes Eco 3(4): 289-296.

17. Adabanija MA, Oladunjoye MA (2014) Geoenvironmental assessment of abandonedmines and quarries in South-western Nigeria. J Geochem Expl 145: 148-168.

18. Mehta PS (2002) The Indian mining sector: Effects on the environment \& FDI inflows. CCNM Global Forum On International Investment.

19. Adams R (2009) Addressing threats from abandoned mines in California communities.

20. Mestre MA (2009) Environmental impact of mine drainage and its treatment on aquatic communities.

21. Vazquez MC, Rodrigues HR, Pelcastre-Villafuerte BE (2012) Risk perception and social articipation among women exposed to manganese in the mining district of the state of Hidalgo, Mexico. Sci Total Environ 414: 43-52.

22. Mbaya RP (2013) Land degradation due to mining : The Gunda Scenario. Int J Geog Geol 2(12): 144-158.

23. Higginbotham N, Freeman S, Connor L, Albrecht G (2010) Environmental injustice and air pollution in coal affected communities, Hunter Valley, Australia. Health and Place 16(2): 259-266. 